\title{
Analysis of Gap Patterns in Longitudinal Rumble Strips to Accommodate Bicycle Travel
}

\author{
Richard C. Moeur
}

\begin{abstract}
Rumble strips can offer significant reductions in run-off-road crashes on rural highways. Newer ground-in rumble strip designs can be installed on a wider variety of shoulders, but these new designs have a much greater negative effect on bicycle traffic than did previous designs. The feasibility of placing gaps in a rumble strip pattern to permit bicycle traffic to cross the rumble strip area without striking the rumble strip pattern itself was investigated. A recommended minimum length for these gaps to accommodate bicyclists of varying abilities at speeds representative of downhill conditions was also determined. On the basis of experimental information collected, the researchers recommend that rumble strips on noncontrolled-access highways include periodic gaps of $3.7 \mathrm{~m}$ (12 ft) in length, and that these gaps be placed at periodic intervals at a recommended spacing of $12.2 \mathrm{~m}(40 \mathrm{ft})$ or $18.3 \mathrm{~m}(60 \mathrm{ft})$.
\end{abstract}

This study is intended to determine the optimum length for gaps in continuous shoulder rumble strips to allow bicyclists traveling on the roadway or shoulder to cross the rumble strip without having to enter the rumble strip pattern.

\section{BACKGROUND}

\section{Shoulder Rumble Strip History}

Many states have installed longitudinal rumble strips on the shoulders of rural highways. These rumble strips have been shown to have a significant effect on drowsy or inattentive drivers, and they have effected reductions of up to 80 percent in the run-off-road crash rate on some rural highways (1).

In the past, many of these rumble strips were installed by placing a special roller on the shoulder during the asphalt concrete paving process, creating a pattern of small indentations approximately 25- to 63 -mm ( 1 - to $2 \frac{1}{2}$-in.) long by 25 -mm (1-in.) deep by 600 - to 900-mm (2- to 3 -ft) wide on 200- to $300-\mathrm{mm}$ (8- to 12 -in.) centers (1). This is what is described as a rolled-in rumble strip. These rumble strips were effective in reducing run-off-road crashes, but were limited in application because of the impossibility of placing them except during the paving of the shoulder surface. Another problem associated with this type of rumble strip occurred when the roller did not track straight along the roadway edge line. This caused the rumble strip pattern to wander laterally across the shoulder, sometimes completely to the far edge of the shoulder.

While it could not be considered enjoyable to operate a bicycle on these rumble strips, they did not cause any significant vertical

Arizona Department of Transportation, Traffic Engineering Group, 206 South 17th Avenue, MD 063R, Phoenix, AZ 85007-3213. motion or instability of the bicycle, because the bicycle wheels rode over the tops of the indentations without dropping completely into the grooves (Figure 1).

\section{New Rumble Strip Design and Its Effect on Bicycles}

Because of the limitations inherent in the rolled rumble strip design, many states-including Arizona-have begun evaluating the use of a new type of longitudinal shoulder rumble strip. This rumble strip consists of grinding $13-\mathrm{mm}(1 / 2-i n$.) deep by $180-\mathrm{mm}(7-i n)$. long cylindrical grooves in the pavement on approximately $300-\mathrm{mm}$ (1-ft) centers (2). These ground-in rumble strips can be installed at any time, on any width shoulder, and on most types of pavement surface. Because of this ease of installation, economical cost, and significant potential to reduce run-off-road crashes, the Arizona Department of Transportation (ADOT) began to install this new type of rumble strip on state highways on an interim basis.

Soon after the installation of these rumble strips in certain areas, bicyclists complained to ADOT that these strips had a much more severe effect on bicycle handling and comfort than did the previous rumble strip design. The reason these new rumble strips have a much greater negative effect on bicyclists is the fact that the wheels of a bicycle riding on the rumble strip drop completely into every groove of the rumble strip. This induces $13 \mathrm{~mm}(1 / 2$ in.) of vertical motion for every $300 \mathrm{~mm}$ (12 in.) of forward motion of the bicycle (Figure 2). The vast majority of bicycles operated on streets and highways do not have any sort of suspension or shock absorption except that provided by the rider, tires, saddle, and handle grips themselves. Because of this, vertical displacements on the roadway have a much more severe effect on bicycles than they do on cars, trucks, or motorcycles.

Because of these concerns, measures were considered to reduce the negative effect of the rumble strip on bicycle travel. At first, it was thought that changing the spacing of the individual grooves might have some beneficial effect, as the bicycle's wheelbase could be interacting with the groove spacing to magnify the vertical motion of the bicycle. A further analysis of this concept showed that the primary problem was the vertical motion of the bicycle itself, and not necessarily the location or period of the motion.

Another suggestion was to reduce the depth of the rumble strip grooving to $10 \mathrm{~mm}(3 / 8 \mathrm{in}$.) in order to reduce the vertical motion associated with the grooving. However, field evaluations of groundin rumble strip installations of this type by H. M. Elliott have indicated that this reduction in depth has little effect on bicyclist comfort and handling. 

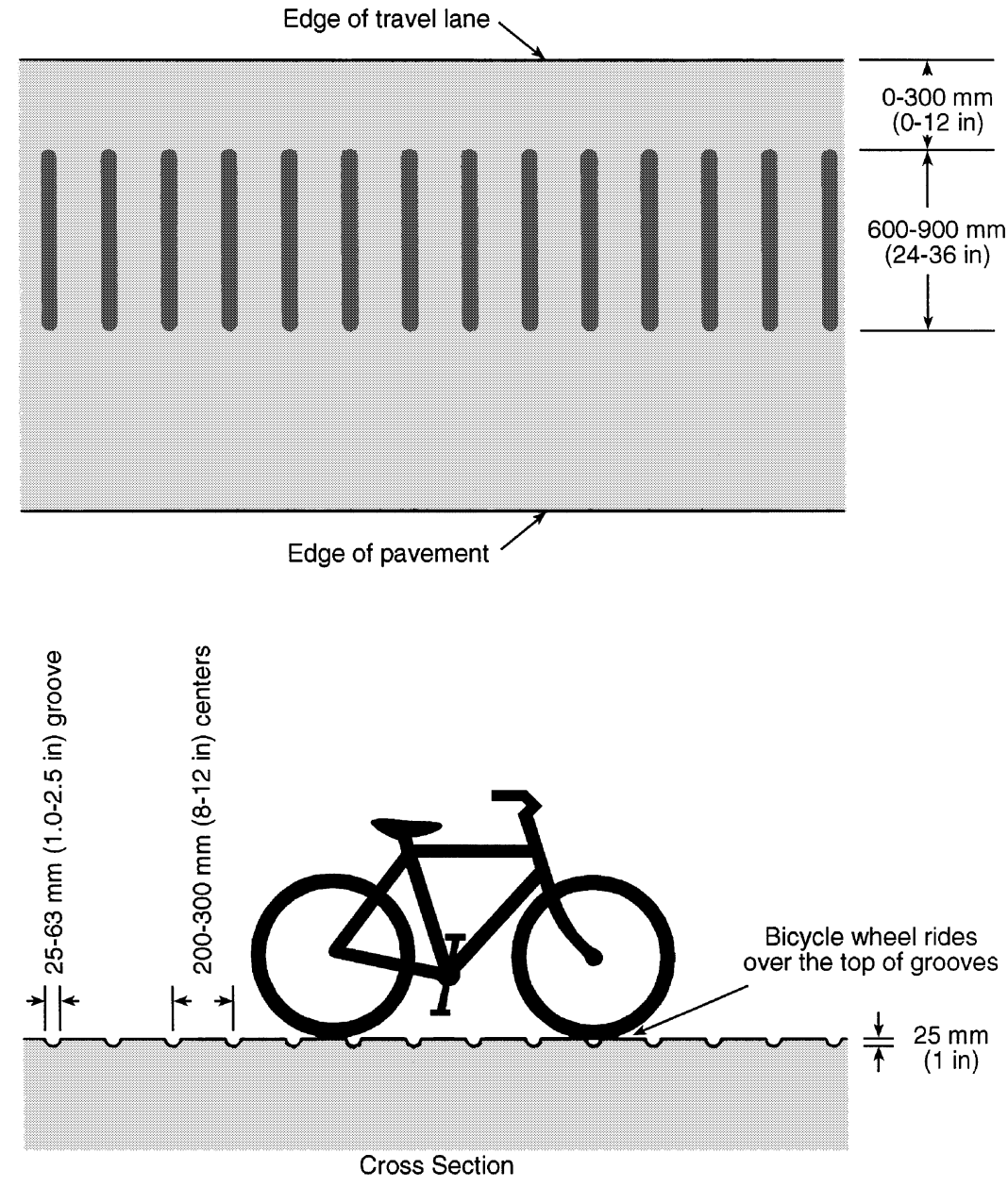

FIGURE 1 Rolled-in rumble strip.

Therefore, a better solution would be the creation of a rumble strip design that contains periodic gaps in the rumble strip grooving pattern. This would satisfy bicyclists' need to cross the rumble strip pattern without causing them to enter the grooved area. These periodic gaps would need to be sufficiently long as to permit a typical bicyclist to cross without entering the grooved area, but not so long as to permit a vehicle tire at a typical run-off-road angle of departure to cross the gap without entering the grooved area.

Placing gaps in rumble strips will serve only to improve opportunities for bicyclists to comfortably cross the rumble strip. If the rumble strip itself is placed in a location where it is near the expected wheel path of bicyclists, such as on a narrow shoulder, the placement of gaps in the rumble strip will provide little benefit to bicycle travel. If the bicyclist rides on shoulders where the rumble strip is concurrent with his or her typical wheel path, then it is likely that the bicyclist will enter the rumble strip pattern during normal operation. In these cases, it is important that the roadway or shoulder (or both) provide adequate travel space for bicyclists without encroachment by the rumble strip pattern.

\section{Do Bicyclists Need to Cross Rumble Strips?}

A question was raised as to whether bicyclists needed to cross rumble strips in the first place. The perception exists that bicyclists do not need to leave the shoulder or enter the travel lane, or that they are always safer while bicycling on the shoulder. This is incorrect for a number of reasons.

First, bicyclists on all roadways in Arizona other than controlled access freeways have the legal right to operate within the rightmost lane, regardless of the presence of a shoulder. Second, shoulders frequently contain obstacles and obstructions, such as parked vehicles, or sand and gravel, broken glass, and other debris. Finally, at rightturn lanes, the potential for conflicts and collisions between through bicyclists and right-turning vehicles is reduced when the bicyclist rides to the left of the right turn lane, and not on a shoulder to the right of a turn lane (3).

\section{Selection of Test Speed}

ADOT intends to place this new style of rumble strip on most rural state highways that have sufficient shoulder width to permit rumble strip installation, especially roads with shoulder width greater than $1.2 \mathrm{~m}$ (4 ft). Many of these highways have downgrades of 5 to 6 percent or greater.

When design is being done specifically for bicycle traffic, AASHTO generally recommends the use of a $32 \mathrm{~km} / \mathrm{h}(20 \mathrm{mph})$ design speed (3). However, bicyclists can easily reach speeds at or above $40 \mathrm{~km} / \mathrm{h}(25 \mathrm{mph})$ on downgrades, so any gap in a rumble 

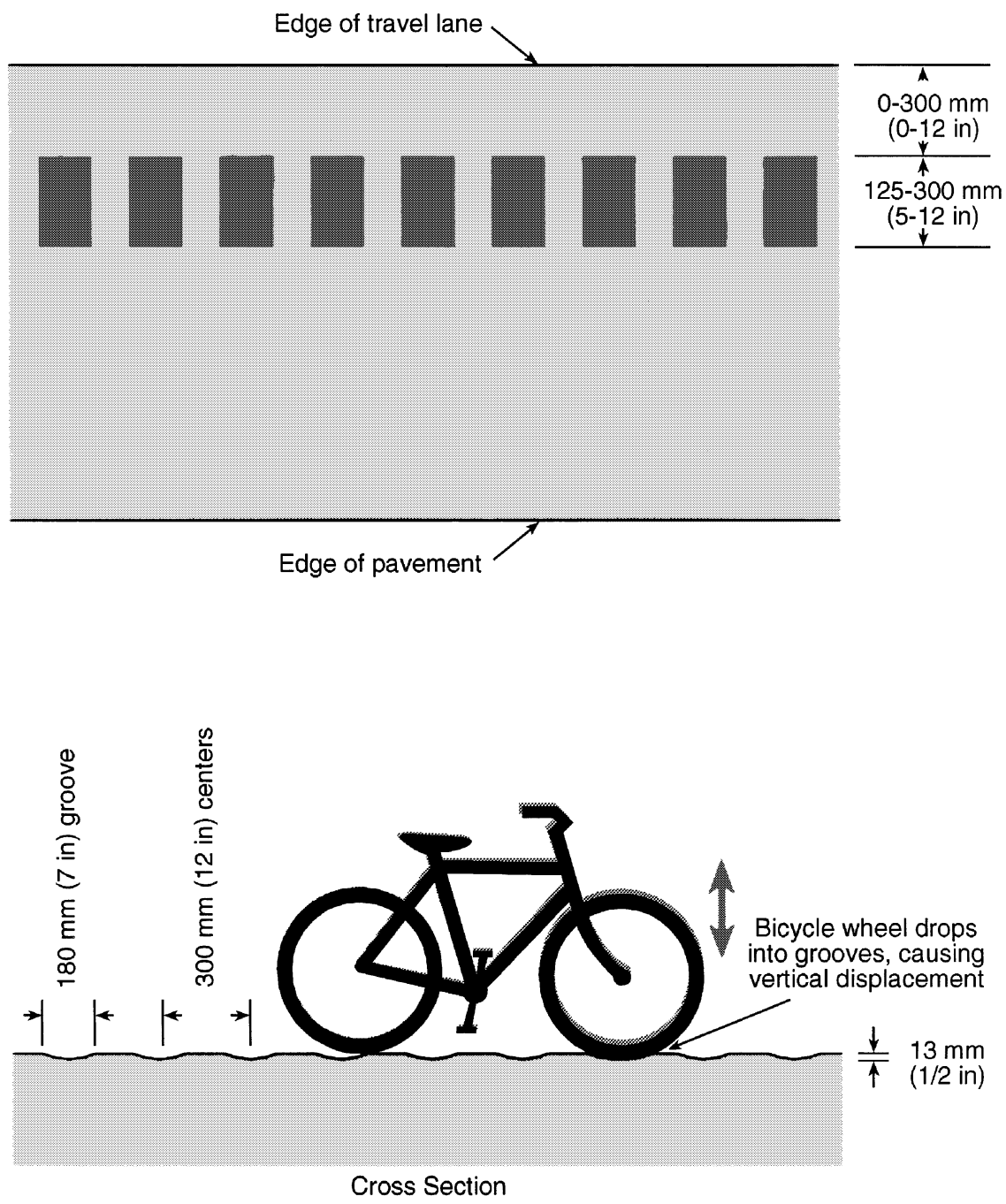

FIGURE 2 Ground-in rumble strip.

strip on downgrades should be designed to accommodate a bicyclist traveling at such a speed. Since such a gap length will also accommodate bicyclists at lower speeds, this length should be serviceable for all locations. For the sake of uniformity, the adopted rumble strip pattern should use this gap in all locations open to bicycle travel.

\section{TESTING METHODOLOGY}

\section{Description of Test}

The testing of various rumble strip gap lengths was performed on March 27 and 28, 1999. The weather was clear and warm. The test site was set up on a residential street in Phoenix, Arizona. The roadway surface consisted of asphalt concrete pavement with no visible cracks, rutting, or other deformities. The roadway had been recently swept and cleaned. That the traffic volume on this roadway was low during the test period ensured that motor vehicle traffic did not affect test results unpredictably.

The rumble strip gap test was placed at the end of a moderate downgrade so that bicyclists entering the test area would typically be traveling at speeds between 37 and $45 \mathrm{~km} / \mathrm{h}$ (23 and $28 \mathrm{mph}$ ) or greater. The downgrade area and test area had no geometric or sight distance restrictions that could affect the test results.

Raised pavement markers placed in a 300-mm (12-in.) wide pattern were used to simulate a rumble strip and gap installation. These markers could easily be moved to vary the length of the gap for testing. This simulated rumble strip was placed at a distance of $1.2 \mathrm{~m}$ $(4 \mathrm{ft})$ from the near edge of the gutter pan. Spot speeds were measured with a calibrated radar gun as the subjects entered the rumble strip test area. Two video cameras were used to record and verify the results of the tests and to provide a visual record of the evaluation (Figure 3).

\section{Test Subjects}

Twenty-eight test subjects of varying skill levels participated. With some prior coordination with ride leaders, the subjects were recruited from bicyclist groups that traveled through the area during the days of the testing. Five of the subjects (18 percent) could be classified as basic bicyclists (4), while seventeen (61 percent) could be classified as skilled bicyclists. Six of the subjects ( 21 percent) could be classified as skilled and experienced bicyclists. While this cross section of 


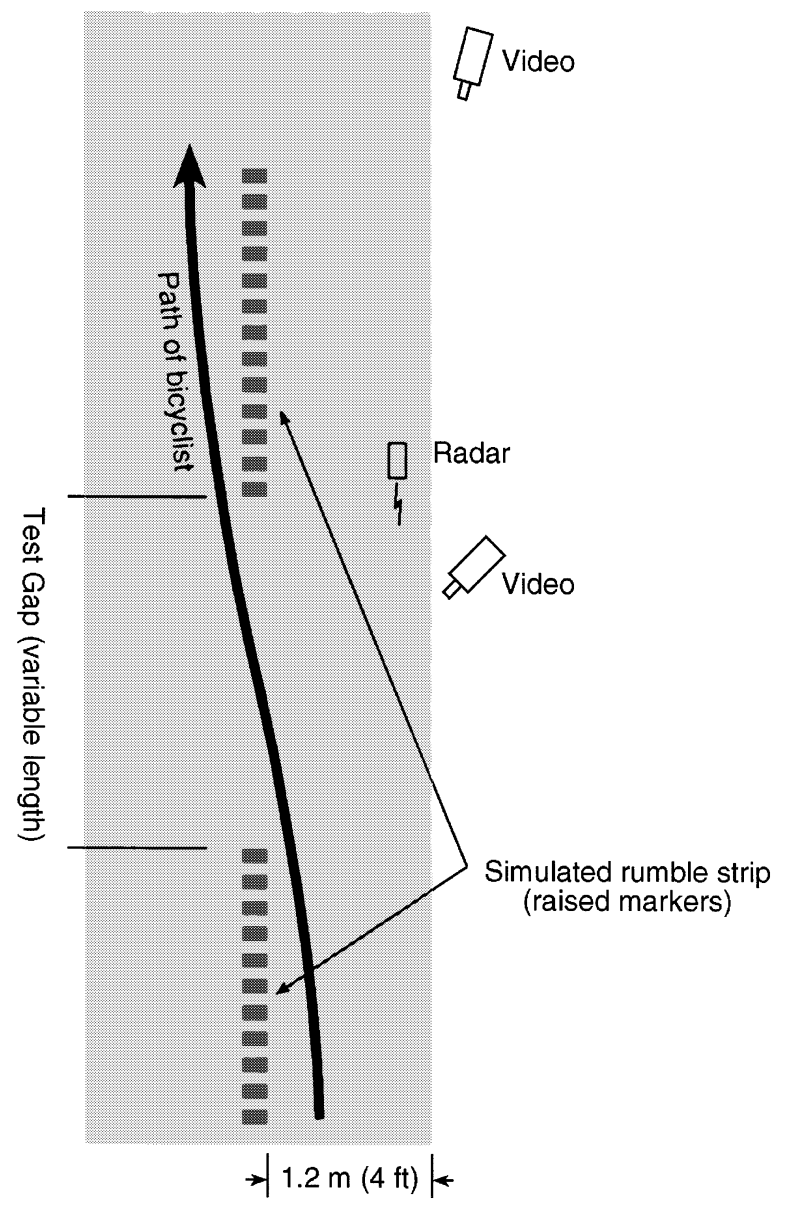

FIGURE 3 Rumble strip gap testing area.

bicyclists may not be fully representative of the entire cycling population, it could be considered to be representative of the population of bicyclists that typically ride on rural state highways, where rumble strips of this type are often installed.

\section{TESTING}

The test subjects were instructed to ride toward the test area at as high a speed as possible, from a location approximately $300 \mathrm{~m}(1,000 \mathrm{ft})$ uphill from the test site. The subjects were instructed to maintain a 15- to 20-s separation between each other (with the exception of one run, noted below) in order to minimize interference with one another.

The first test sequence evaluated a wide range of gap spacings, so that a smaller set of spacings could be focused on during further study. A group of four bicyclists of moderate to high skill levels (Group 1) tested a variety of gap spacings. Each bicyclist made two runs at a 6.1-m (20-ft) gap spacing; then each bicyclist made one run each at 5.5-m (18-ft), 4.9-m (16-ft), 4.3-m (14-ft), 3.7-m (12-ft), and 3.0-m (10-ft) spacings. The bicycles in this group consisted of one cruisertype bicycle, two road bicycles, and one touring bicycle. All of the subjects cleared all tested distances without striking the rumble strip. The test subjects expressed no difficulty with clearing the gap lengths at all distances down to $3.7 \mathrm{~m}$ (12 ft), but some of the subjects did state that the 3.0-m (10-ft) gap seemed "rather tight" for the test speeds.
Since 100 percent of the test subjects consistently cleared all the measured gaps at speeds in the vicinity of $40 \mathrm{~km} / \mathrm{h}(25 \mathrm{mph})$ down to a distance of $3.0 \mathrm{~m}(10 \mathrm{ft})$, the spacings greater than $3.7 \mathrm{~m}(12 \mathrm{ft})$ were rejected. The 3.0- and 3.7-m (10- and 12-ft) gap spacings were selected for further study.

The second test sequence utilized a larger number of test subjects to evaluate the 3.0- and 3.7-m (10- and 12-ft) gap spacings in order to determine which of these would be the optimum spacing for general use. Four different groups of bicyclists tested these spacings.

A group of eight bicyclists of moderate to high skill levels (Group $2 a$ ) tested the $3.7-\mathrm{m}(12-\mathrm{ft})$ and $3.0-\mathrm{m}(10-\mathrm{ft})$ gaps, making one run each at each spacing. The bicycles in this group consisted of road and racing bicycles, with one short wheelbase recumbent bicycle. All subjects cleared both distances without striking the rumble strip. This group of test subjects expressed no difficulty with the 3.7-m (12-ft) gap length, but some of the subjects stated that they perceived the 3.0-m (10-ft) gap to be "too tight" for "real-world" conditions.

A group of seven bicyclists of basic to moderate skill levels (Group 2b) then tested a 3.0-m (10-ft) gap, making one run each. The bicycles in this group consisted of one mountain bike and six road bicycles. Eighty-six percent of the subjects cleared this distance without striking the rumble strip, with one subject failing to move to cross the strip.

The two groups listed above were then instructed to ride through the test area in small groups of two to four bicyclists. This was done to evaluate whether cycling in a group had a significant effect on the ability to cross the rumble strip. On the basis of concerns expressed by some of the group during the 3.0-m (10-ft) test, the gap spacing

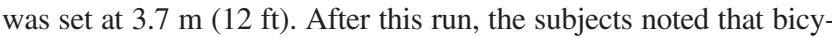
clists in the back of a group could not clearly see the location of the gap in the rumble strip, but could obtain visual cues about the location of the gap from the motions of the other subjects in the group. This was verified in a review of the videotape. The net effect of this was that 100 percent of the bicyclists in all these groups were able to cross the gap without striking the rumble strip.

A group of six bicyclists of basic to moderate skill levels (Group 3) tested the 3.7-m (12-ft) gap, making two runs each. The bicycles in this group consisted of road and racing bicycles, along with one long wheelbase recumbent bicycle. One hundred percent of the subjects cleared both distances without striking the rumble strip. After testing the 3.7-m (12-ft) gap twice, this group of test subjects refused to test a 3.0-m (10-ft) gap spacing, stating that they felt uncomfortable in testing any gap smaller than the one recently tested.

A group of two bicyclists of moderate skill level (Group 4) tested the 3.7-m (12-ft) gap, making two runs each. The bicycles in this group consisted of one road bicycle and one touring bicycle. One hundred percent of the subjects cleared the gap distance without striking the rumble strip.

A group of two bicyclists of high skill level on one tandem bicycle (Group 5) tested the 3.7-m (12-ft) gap, making two runs. In the first of these tests, the subjects did slightly enter the far side rumble strip area, but successfully navigated the gap on all runs.

Results for test runs, gaps, and speeds are summarized in Table 1.

\section{DISCUSSION OF RESULTS}

\section{Effect of Bicycle Type on Results}

As noted earlier, a number of different bicycle types were used in this test, including road, racing, touring, hybrid, mountain, cruiser, short and long wheelbase recumbent, and tandem bicycles. There were no 
TABLE 1 Summary of Test Runs, Gaps, and Speeds

\begin{tabular}{|c|c|c|c|c|c|c|c|c|c|c|}
\hline Group & Run & $\begin{array}{l}\text { No. in } \\
\text { Group }\end{array}$ & $\begin{array}{c}\text { Bicycle } \\
\text { Types }\end{array}$ & $\begin{array}{c}\text { Gap } \\
\text { (m) }\end{array}$ & $\begin{array}{l}\text { Speed } \\
\text { Range } \\
(\mathbf{k m} / \mathbf{h})\end{array}$ & $\begin{array}{c}\text { Average } \\
\text { Speed } \\
(\mathbf{k m} / \mathbf{h}) \\
\end{array}$ & $\begin{array}{c}\text { Gap } \\
\text { (ft) }\end{array}$ & $\begin{array}{l}\text { Speed } \\
\text { Range } \\
\text { (mph) }\end{array}$ & $\begin{array}{c}\text { Average } \\
\text { Speed } \\
\text { (mph) }\end{array}$ & \% Pass \\
\hline \multirow[t]{7}{*}{1} & 1 & 4 & COR & 6.1 & $32-39$ & 35.9 & 20 & $20-24$ & 22.3 & $100 \%$ \\
\hline & 2 & & & 6.1 & $35-45$ & 41.0 & 20 & $22-28$ & 25.5 & $100 \%$ \\
\hline & 3 & & & 5.5 & $35-45$ & 41.4 & 18 & $22-28$ & 25.5 & $100 \%$ \\
\hline & 4 & & & 4.9 & $35-45$ & 41.4 & 16 & $22-28$ & 25.8 & $100 \%$ \\
\hline & 5 & & & 4.3 & $37-42$ & 40.2 & 14 & $23-26$ & 25.0 & $100 \%$ \\
\hline & 6 & & & 3.7 & $35-43$ & 40.2 & 12 & $22-27$ & 25.0 & $100 \%$ \\
\hline & 7 & & & 3.0 & $37-42$ & 39.4 & 10 & $23-26$ & 24.5 & $100 \%$ \\
\hline \multirow[t]{2}{*}{$2 a$} & 1 & 8 & A R S & 3.7 & $39-50$ & 44.1 & 12 & $24-31$ & 27.4 & $100 \%$ \\
\hline & 2 & & & 3.0 & $40-50$ & 45.1 & 10 & $25-31$ & 28.0 & $100 \%$ \\
\hline $2 b$ & 1 & 7 & M R & 3.0 & $35-45$ & 39.4 & 10 & $22-28$ & 24.5 & $86 \%$ \\
\hline $2 \mathrm{ab}$ & 1 & 15 & A M R S & 3.7 & $37-48$ & 41.8 & 12 & $23-30$ & 26.0 & $100 \%$ \\
\hline \multirow[t]{2}{*}{3} & 1 & 6 & A L R & 3.7 & $23-37$ & 32.4 & 12 & $14-23$ & 20.2 & $100 \%$ \\
\hline & 2 & & & 3.7 & $23-37$ & 30.6 & 12 & 14-23 & 19.0 & $100 \%$ \\
\hline \multirow[t]{2}{*}{4} & 1 & 2 & OR & 3.7 & $31-35$ & 33.0 & 12 & $19-22$ & 20.5 & $100 \%$ \\
\hline & 2 & & & 3.7 & $31-32$ & 31.4 & 12 & $19-20$ & 19.5 & $100 \%$ \\
\hline \multirow[t]{2}{*}{5} & 1 & 2 (on 1 & $\mathrm{~T}$ & 3.7 & 37 & 37.0 & 12 & 23 & 23.0 & $100 \%$ \\
\hline & 2 & bicycle) & & 3.7 & 39 & 38.6 & 12 & 24 & 24.0 & $100 \%$ \\
\hline \multicolumn{11}{|c|}{ Bicycle types: } \\
\hline C: Cruise & & & O: Tou & & $\mathrm{T}$ : & Tandem & & & & \\
\hline
\end{tabular}

significant differences between bicycle types with respect to travel path through the gap or ability of the bicyclist to traverse the gap.

\section{Simulation of Rumble Strip Versus Actual Rumble Strip}

This test was conducted with a simulated rumble strip that consisted of raised markers, and not in a location with actual rumble strips. The reason this arrangement was used was so that the length of the gap could be quickly and readily changed, without experimenters' having to fill in grooves on an existing rumble strip or install grooves on short notice.

There may be a concern regarding the greater visibility of the raised markers used in the test versus the ground-in grooves that will actually be installed on highways. However, field surveys have indicated that the ground-in shoulder grooves are easily visible under conditions typical for bicycle travel on state highways. Also, a repetitive pattern of gaps in a shoulder rumble strip pattern will make locating of gaps much easier for bicyclists when they travel in these areas.

\section{Path of Bicyclists Through Test Area}

When crossing the rumble strip gap, bicyclists typically began their movement approximately $0.6 \mathrm{~m}(2 \mathrm{ft})$ to the right of the rumble pattern, and then turned smoothly to cross the gap diagonally (Figure 3), then steered slightly to resume their movement parallel to the rumble strip on the opposite side. The total lateral movement for most

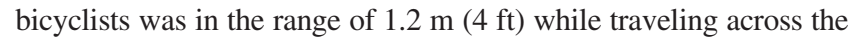
gap. From video analysis, there seemed to be little correlation between lateral movement and bicycle type or bicyclist skill level.

\section{Rumble Strip Width Versus Gap Length}

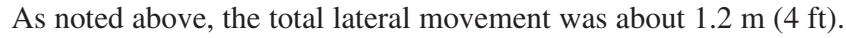
This is significantly larger than the width of the rumble strip tested.
From video analysis of the motion of the bicycles through the gap, the movement across the rumble strip appears to be governed by the length of the gap, not by the width of the gap. Changing the rumble strip width to $200 \mathrm{~mm}$ ( 8 in.) or $125 \mathrm{~mm}$ (5 in.) should affect neither the lateral movement of the bicyclist nor the necessary length needed for crossing. Therefore, the same length of gap should be used for all widths of rumble strips up to $300 \mathrm{~mm}$ (12 in.). Since the maximum rumble strip width proposed in Arizona is $300 \mathrm{~mm}$ (12 in.), the need for longer gap lengths corresponding to wider rumble strips was not evaluated in this study.

\section{Frequency of Gaps}

A regular pattern of these gaps should be established, so that bicyclists will have frequent opportunities to cross the rumble strip pattern. Also, a regular pattern of gaps will make it easier for bicyclists to find gaps when necessary.

The question then becomes one of selecting the proper cycle length for ease of construction. A 3.7-m (12-ft) gap in an 18.3-m (60-ft) cycle will result in 80 percent coverage of the shoulder with rumble strips, and is exactly one-and-one-half times cycle length for lane line striping recommended by the Manual on Uniform Traffic Control Devices (MUTCD). A 12.2-m (40-ft) cycle, consisting of a 8.5-m (28-ft) long rumble strip with a 3.7-m (12-ft) gap, should also be considered for use. This generally coincides with the MUTCD-recommended cycle for rural lane line marking. This pattern provides 70 percent coverage of the total shoulder length with rumble strip.

At a speed of $24 \mathrm{~km} / \mathrm{h}(15 \mathrm{mph})$ and a spacing of $18.3 \mathrm{~m}(60 \mathrm{ft})$, a bicyclist will encounter a gap in the rumble strip every $2.7 \mathrm{~s}$. At

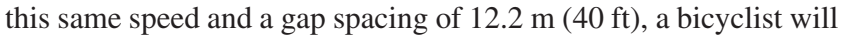
encounter a gap every $1.8 \mathrm{~s}$. Both these patterns should provide gaps at sufficient frequency to permit bicyclists to cross the rumble strips in advance of hazards or intersections, though the 12.2-m (40-ft) spacing will provide gaps more frequently for a given speed. At higher speeds, gaps will be encountered more frequently, regardless of spacing. 


\section{OTHER ISSUES}

\section{Effect of Gap on Motor Traffic}

Placing a gap in a rumble strip pattern introduces the possibility that a vehicle could pass over the gap in the rumble strip as it departs the roadway, negating the benefit of the rumble strip. According to other studies, the typical departure angle for run-off-road crashes is approximately 3 degrees (5). At an angle of 3 degrees, the center of the critical tire (typically the right front tire) will travel $190 \mathrm{~mm}$ (7.5 in)

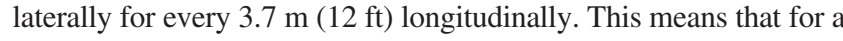
typical run-off-road crash at a 3-degree angle, it will be impossible for the tire to completely miss a $200-\mathrm{mm}$ (8-in.) or 300-mm (12 in.) rumble strip, if a $3.7-\mathrm{m}$ (12-ft) gap is used. When the width of the tire, typically $200 \mathrm{~mm}$ (8 in.) for a passenger motor vehicle tire, is factored in, it becomes impossible for the tire to completely miss a $3.7-\mathrm{m}(12-\mathrm{ft})$ gap in a rumble strip as narrow as $125 \mathrm{~mm}$ (5 in.) or less.

\section{Effect of Gap on Cost and Constructibility}

Inclusion of these gaps may require the rumble strip contractor to place marks on the pavement to define the gaps, if the rumble strip installation machine cannot be programmed to provide these gaps automatically, or if the gaps cannot be synchronized with existing marking cycles. On the basis of discussions with rumble strip contractors, inclusion of these periodic gaps should have a minimal effect on the total cost of rumble strip installation, with cost savings from reduced rumble strip cutting offset by cost increases due to increased mobilization and layout needs.

\section{Rumble Strips on Controlled-Access Highways}

It is recognized that bicyclists are permitted to use the shoulders of fully-controlled-access highways in most rural areas in Arizona, and that there may be situations in which the bicyclist may need to cross the rumble strip. However, these controlled-access highways also have the highest potential for high-speed run-off-road crashes. Bicyclists in Arizona are not legally empowered to use the travel lanes of these controlled-access highways, despite their rights on other roadways. Therefore, continuous rumble strips may still be warranted on fully-controlled-access highways where sufficient clear shoulder width exists for bicycle travel after rumble strip installation.

\section{CONCLUSIONS AND RECOMMENDATIONS}

The results of the testing indicate that a 3.7-m (12-ft) gap will perform acceptably to permit bicyclists to cross a ground-in rumble strip pattern. Either a $12.2-\mathrm{m}(40-\mathrm{ft})$ or $18.3-\mathrm{m}(60-\mathrm{ft})$ cycle for the rumble strip and gap will serve well in terms of ease of construction and convenience for bicyclists. The $18.3-\mathrm{m}$ (60-ft) cycle will provide greater rumble strip coverage, while the $12.2-\mathrm{m}(40-\mathrm{ft})$ cycle will provide more frequent gaps with a small difference in coverage.
Rumble strips installed on noncontrolled-access roadways should include these gaps, as bicyclists will be using these roadways and will need to cross the rumble strips. The same gap length and cycle should be used for all widths of rumble strips.

\section{FUTURE RESEARCH NEEDS}

Whereas this study did determine an acceptable gap length in rumble strips to accommodate bicyclists, there are still quite a number of future research opportunities regarding bicycles and rumble strips, including

- Evaluation of new and improved rumble strips and pavement markings (such as profile thermoplastic edgeline marking) that may have fewer negative effects on bicyclists while still providing adequate warning to errant motor vehicle operators;

- Verification of this study's findings on actual grooved rumble strip and gap sections;

- Verification of acceptable gap lengths for different cycling populations and different operating speeds;

- Analysis of lateral movement across rumble strips and gaps versus shoulder width rumble strip width, and so on;

- Analysis of the interaction and effect of rumble strip grooving on bicycle handling, stability, and safety; and

- Analysis of the relative effect of continuous versus intermittent rumble strip designs on motorist warning and guidance.

\section{ACKNOWLEDGMENTS}

This study was sponsored by and produced under the authority of the ADOT Traffic Engineering Group, which provided support, resources, and materials necessary for this study. Further appreciation is expressed to the Arizona Bicycle Club, which supplied the majority of the volunteers for the testing, and to Seth Chalmers of TASK Engineering, Inc., who provided technical guidance and the raised markers used in the study.

\section{REFERENCES}

1. NCHRP Synthesis of Highway Practice 191: Use of Rumble Strips to Enhance Safety. TRB, National Research Council, Washington, D.C., 1993.

2. Draft Longitudinal Shoulder Grooving Details. Arizona Department of Transportation, Phoenix, 1997.

3. AASHTO Guide for Development of Bicycle Facilities. AASHTO, Washington, D.C., 1999.

4. Selecting Roadway Design Treatments to Accommodate Bicyclists. FHWA, U.S. Department of Transportation, Washington, D.C., 1994.

5. Portland Cement Concrete Shoulders. Research and Development Report No. 27. Illinois Division of Highways, Department of Public Works and Buildings, Springfield, 1970.

Publication of this paper sponsored by Committee on Bicycling, Subcommittee on Research, Policy, and Implementation. 